Polish universities

\title{
Setback for liberalization
}

Warsaw

WARSAW University's new rector, Dr Grzegorz Bialkowski, a physicist and nonParty "moderate", was elected last week in place of the "liberal" Dr Klemens Szaniawski, whose election, last May, was vetoed by the Minister of Science, Higher Education and Technology, Dr Benon Miskiewicz. The elections took place under democratic procedures laid down during the Solidarity era, procedures which, it is feared, will shortly be modified to increase ministerial control.

The liberalization of higher education under Solidarity was embodied in a new Higher Education bill which was not in the event made law until May 1982, five months after the declaration of martial law. By that time a number of amendments had been introduced, strengthening the power of the minister to overrule university decisions. Last May, Dr Miskiewicz used these powers to veto the elections of the rectors of four institutions (Warsaw, Wroclaw and Poznan Universities and the Higher School of Fine Arts). When Warsaw University tried to resist, the minister simply suspended the university's electoral college for six months and extended the term of the retiring rector, Dr Kazimierz Dobrowolski.

Hopes that such ministerial interventions would be kept to a minimum were raised at the beginning of the current academic year, when it was announced that the suspension of the electoral council would be lifted and new elections held as soon as the six months had expired. This optimism, however, was considerably reduced a few weeks later when documents began to circulate in Warsaw and other university towns setting out what purported to be proposed changes to the 1982 Higher Education on Act, which would considerbly curtail university autonomy. The alleged changes included: reduction of the election of rectors to a choice between two candidates nominated by the minister; strengthening of the powers of the minister to suspend lecturers and/or collegiate bodies if he deems that they have been acting "contrary to the interests of society" . virtual abolition of participation by students and junior staff in decisionmaking within the university; reorganization of the samorzad, the nonaligned students' "'self-government body", on the basis of existing student and youth organizations, all of which are Party-orientated.

Such allegations, Miskiewicz announced, were entirely false and "provocative". Nevertheless, in a meeting with the Main Council for Science and Higher Education on 15 November, he outlined his own proposals for amending the $1982 \mathrm{act}$, which according to participants were simply the proposals of the "provocative" document in somewhat less specific form. The Main Council, which consists of one delegate from every state institution of higher education in Poland, strongly opposed the changes, noting that the 1982 act is, for "a significant fraction of the university milieu", the symbol of academic autonomy, and urging that to change a law barely two years after it came into force can only lead to a sense of doubt and instability. Even the least disapproving of the Main Council members are said to take the view that the law should be allowed to stand at least for another three years (a rector's term of office) and that any amendments should then be based on consultations and open discussions.

Students, of course, are particularly perturbed by the proposed reform of the samorzady, which would effectively transfer into Party hands both such consultations on university policy as would still be left to the students after the reforms and also a whole range of welfare and social matters. Although the $\mathbf{1 9 8 2}$ act forbids the formation of samorzad structures above the level of the individual university, representatives of the samorzady of all Polish universities and high schools met recently in Poznan to discuss the threatened changes. This technically illegal meeting was allowed to take place, although all participants had their identity documents checked by security police patrols in the vicinity of the assembly point. Although the content of the meeting remains confidential, it is understood that the samorzady as, for the moment, legally-constituted organizations, hope to be able to voice their concern through the peaceful consultative procedures provided by the 1982 act, and to restrain the more radical student elements from such proscribed activities as strikes and demonstrations.

Vera Rich

\section{European cooperation All-optical computer in sight}

Brussels

THE European all-optical computer is just around the corner or, more precisely, less than a year away. Following a major development in optical logic gates, demonstrated in London in November and in Brussels last week, the prototype of the all-optical computer is to be built at Edinburgh's Heriot-Watt University by a team headed by Professor Desmond Smith.

The operation is part of two-year project in the field of all-optical information processing based on the concept of optical bistability. Eight research teams have collaborated in the European Joint Optical Bistability Project, which will cost 1.8 million European Currency Units (ECU) - about $£ 1$ million. They work at the Université Libre de Bruxelles (Belgium); University College Dublin (Ireland); the Centre National de la Recherche Scientifique in Strasboug (France); the Universities of Milan, Pisa and Florence (Italy); the University of Frankfurt, the Fraunhofer Institute of Instrumental Physics in Freiburg, the Max Planck Institute of Quantum Optics in Munich and the Technical University of Berlin (West Germany); and the Royal Signals and Radar Establishment, Malvern (United Kingdom). The teams were brought together by the Community's Committee for the European Development of Science and Technology (CODEST) which promotes cooperation between research institutes and scientists.

In Nature last January (307, 315; 1984), Professor Smith described new developments in optical bistability and the coupling of optical logical gates, in the infrared spectrum at cryogenic temperatures, which can switch with milliwatt laser beam power and give sufficient output to switch further interconnected elements.

The latest breakthrough involves the coupling of optical gates at visible wavelengths using the semiconductor zinc selenide, one of the many new materials tested, at room temperature. The immediate advantage of the process is that it greatly facilitates construction and could revolutionize computer design. It could also be used in arrays and displays.

The technology is similar to that used in interference filter technology: the thermally-evaporated thin films are cheap and easy to produce and, being uniformly thick, can be used, unlike to earlier technology, for large array systems and twodimensional devices.

The disadvantage is that the use of thermal effects slows down the process but, says Professor Smith, the possibility of having many elements in parallel will increase overall speed. Limitations, he says, are now only likely to be in the order of submicroseconds or even tens of nanoseconds.

There will be benefits in processing information from radar arrays, sonar devices and video signals, he says. Eventually it might be possible to make serial parallel conversions and to store signals in optics for longer periods of time, in fact to improve all computing processes that benefit from parallelism (for example, pattern recognition input devices reading information in parallel). Optically bistable devices could also be a better means of translating fibre optics signals.

According to Professor Smith, it will now be possible "to begin to construct digital optical circuits more complicated than demonstrated with two elements and go on from there to create optical computer architecture"'. 